\title{
Gestão Econômica na Inovação Tecnológica
}

A economia brasileira, com a abertura comercial e financeira, tornou-se mais suscetível ás intempéries da economia internacional e aos fluxos internacionais de negócios, ainda mais com abertura do mercado interno para o setor externo e as mudanças do regime cambial. $\mathrm{O}$ processo de globalização, principalmente a globalização das finanças, independente do segmento de atuação, forçou as companhias brasileiras, a se reestruturarem tanto nos seus procedimentos produtivos quanto nos procedimentos administrativos e por consequência repensarem em gestão econômica e ou financeira.

No que tange a gestão econômica na inovação tecnológica temos que focar em responder perguntas fundamentais: No que investir? Quanto investir? Com que recursos investir?

No que investir? Para tanto é útil considerar a relação custo $\mathrm{x}$ risco $\mathrm{x}$ benefício, qual área será inovada (processo, produto, organização, ou mercado) e se será uma inovação incremental, revolucionaria ou radical. Riscos maiores implicam na possibilidade de alguns projetos falharem, enquanto outros serão bem sucedidos, sendo que estes compensarão as perdas. Desta forma a avaliação deve ser considerada de maneira global e não de forma avulsa. Neste ponto é evidente que o porte da companhia pode limitar a perspectiva global, pois companhias de pequeno e médio porte, um único projeto que falhe pode ter implicações drásticas na sua gestão econômica. É notável que quanto maior o porte da companhia maior a sua capacidade de assumir riscos, sendo assim o porte da empresa pode afetar a estratégia gerencial da inovação.

Considerando os riscos $\mathrm{x}$ custos a inovação incremental é uma estratégia gerencial de grande potencial, pois se inicia de algo conhecido que será aprimorado, cujos riscos de insucessos são menores que a inovação revolucionária ou radical, onde geralmente busca-se um novo paradigma ao segmento de mercado, modificando o modelo de negócios vigente.
Quanto investir? Depois de criada a metodologia que mapeará as possíveis inovações e classifica-las de acordo com sua relevância é o momento de decidir quanto investir em cada projeto, para tanto deve ser previstos os custos necessários para a realização de cada projeto. No geral tais custos são referentes a investimentos em:

- equipamentos e tecnologias;

- investigação e experimentação;

- produção de pilotos e testes;

- projeto e concepção;

- marketing e

- outros.

Esta análise de custos permite concluir que a organização das atividades de inovação nas companhias devem levar em conta a complexidade e multidisciplinaridade que a inovação bem sucedida exige. Deste modo o conhecimento "técnico" e suas competências são os elementos que permitem responder ao mercado com um máximo de eficácia e rentabilidade, retirando daí as vantagens competitivas. É possível inovar em um serviço ou processo sem gerar custos para a empresa, porém por outro lado, uma companhia que deseja implantar uma cultura de inovação certamente terá de reservar recursos financeiros para implementar as ideias e processos ou então investir em pesquisa.

"Inovar não é só comprar máquinas modernas e desenvolver um produto novo, ele deve estar alinhado às necessidades do mercado."

Com que recursos? Em países que ocupam o topo no ranking de inovações o investimento em Pesquisa e Desenvolvimento é realizado predominantemente pelos agentes privados, ao contrário do Brasil, onde 
predomina o apoio estatal à medida que o governo auxilia a superar os gaps tecnológicos e se propõe a compartilhar os riscos intrínsecos aos projetos de inovação tecnológica.

A Estratégia Nacional para Ciência, Tecnologia e Inovação (Encti) prevê para o período de 20122015 que a proporção de investimento em pesquisa e desenvolvimento, em relação ao produto interno bruto (PIB) seja 1,8\%. Os dados mais atualizados são de 2010 , em que $1,16 \%$ do PIB foi destinado à pesquisa e desenvolvimento, sendo que cerca de $53 \%$ refere-se a investimentos públicos e $47 \%$ privados. Verifica-se ainda que os mecanismos de incentivo à inovação do Governo Federal têm apresentado resultados positivos, mesmo com o cenário econômico atual. Ao longo dos anos mais empresas se estruturam para o desenvolvimento de uma cultura de inovação, o que garante a competitividade das empresas brasileiras no contexto global.

No que se refere ao apoio estatal podemos mencionar as linhas de financiamento e incentivos fiscais.

O Banco Nacional do Desenvolvimento Econômico e Social (BNDES) e a Financiadora de Estudos e Projetos (FINEP) são as principais fontes estatais de financiamento e fomento a inovação. Como exemplo podemos citar os seguintes programas BNDES-PSI Inovação, BNDES CRIATEC, FINEP Inova Brasil, FINEP Inovar Fundos e FINEP Tecnova, etc.

Como incentivos fiscais a Lei do Bem (lei 11.196 de 21 de novembro de 2005) que prevê incentivos fiscais para empresas que desenvolvam inovações tecnológicas em território nacional, sendo que para usufruir na totalidade destes incentivos as empresas devem possuir regime de tributação pelo lucro real e os gastos de P\&D devem ser controlados em contas contábeis especificas. Considerando que a inovação tecnológica é geradora de vantagens competitivas, inovar torna-se essencial para a sustentabilidade das empresas, sendo que é por meio delas que as tecnologias, invenções, produtos chegam ao mercado.

São evidentes as vantagens que a inovação traz, porém a implantação de uma cultura de inovação deve ser baseado em uma sólida gestão financeira, para que se crie um circulo continuo que proporcione acesso a novos mercados, novas parcerias, aumento de receitas e novos conhecimentos para as empresas e até para os países.

\section{Eduardo S. Louzada \& Fabio S. Julião}

Faculdade de Tecnologia SENAI Roberto Mange, CEP 75113-630, Anápolis, GO, Brasil.

e-mail: eduardo.louzada@hypermarcas.com.br 